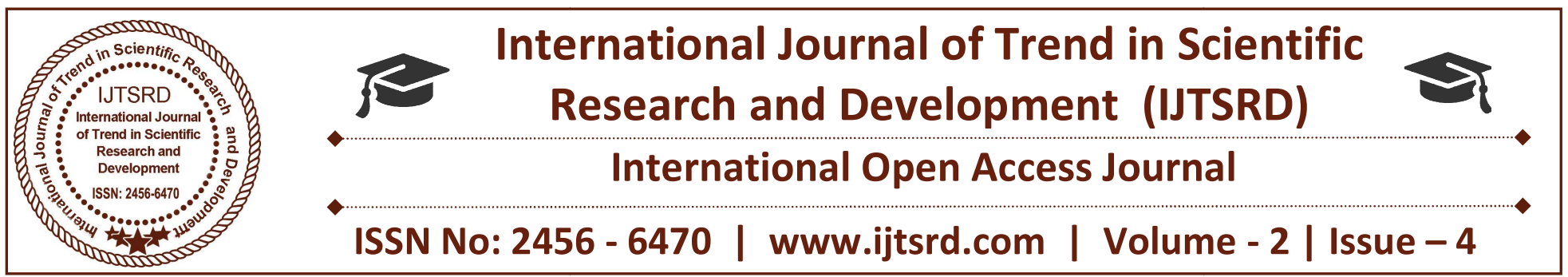

\title{
Linear Programming Techniques to Optimize Bank of Baroda's Loan Portfolio
}

\author{
Kashyap M. Gupta \\ Assistant Professor, Department of Science \& Humanity (Mathematics), \\ Vadodara Institute of Engineering, Kotambi, Vadodara, Gujarat, India
}

\begin{abstract}
The banking industry is one of world's leading industries. Being a commercial bank, giving loans is the primary activity and bank's managers in a competitive environment, make decisions about distribution of financial assets. Taking deposits from the public and loans to customers in form of contracts is the main functions of banks now a days, so the banks should respond to the demands of customers for loans with considering all type of risks, because the most important reason of the bank's failure has been problem of loans portfolio management. So one of important questions that have been raised in context of asset management is how much the optimal size of each type of facilities should be? In the other words, the main object of this paper is answering to question that how much loans maximize return and minimize the risk in a portfolio management structure. According to linear programming approach, we can obtain the optimal loans portfolio and support bank's managers in their related decision making.
\end{abstract}

\section{Keywords: Optimal loan portfolio, LP, Risk, Return}

\section{INTRODUCTION}

Lending to firms is the basic business activity for every commercial bank. This means that loans portfolio management is the most important activity for getting the maximum return and minimum risk from banking loans. It is an indisputable fact that most banks operating in Iran are faced with the complex problem of how to manage their loans portfolio in such a manner that the goals of the bank are best achieved. According to Cohen and Hammer
(1967), what makes task of allocation difficult is finding an appropriate balance between three desirable objectives in loans portfolio management(1). These objectives are; profitability, liquidity and safety. Generally, four major factors influence the asset portfolio management behavior of banks. These factors are government regulations, safety of deposits, and credit demand as well as income aspirations of shareholders. In the recent years, there has been a large development in bank's portfolio management methods. Banks should decide for the loans portfolio, which should be determined by the needs of the firms, market competition and the capacity of the bank(1). Moreover, they should decide on the distribution of its capital among the various sorts of loans, which differ in duration and risk and are affected by the environment, the borrowers' deposits at the given bank as well as other factors (Klaassen, 1998). In addition, banking loan decisions require the use of huge and various data and substantial processing time to be able to serve a large number of variables and a variety of different cases related to different customers (Eletter et al, 2010). This paper proposed a method, based on a linear programming to maximize return with regarding $\operatorname{risk}(2)$.

\section{A. Types of Loans In Bob}

Borrowing money from the bank is called a bank loan. Loans constitute the most significant operation of commercial banks. A well planned loan policy is essential for the successful performance of the credit policy of a bank, for the acquisition of high return and 
the minimization of the risk that originates in credit extension (Klaassen, 1998)(3).

A loan is a type of debt, like all debt instruments, a loan entails the redistribution of financial assets over time, between the lender and the borrower. These contracts may seem similar to conventional banks but they are differing in the core of business in the short and long term as well as in contract agreement. In this paper we define four contracts: Partnership, Future buying, change of ownership and Good credit score that will be mentioned briefly.

1. Partnership between two parties where they both provide capital for a project that they both can manage, normally for limited duration, and is formed to carry out certain projects or investments. It is very similar to the western style of joint venture. Profits are shared according to the ratios determined in the agreement and losses are shared equally according to equity participation(5).

2. Future buying contract refers to an agreement to purchase, at a predetermined price, a specified kind of commodity not available with the seller. The commodity is to be delivered on a specified future date in specified quantity and quality. The difference between future buying and a conventional forward sale is that the price of the commodity must be received at the time of agreement.

3. Change of ownership is the transfer of ownership between two parties.For example, in a car financing facility, a customer leases the car from the owner (bank) at an agreed amount over a specific period. When the lease period expires the customer own the car at an agreed to price(5). The bank generates a profit by determining in advance the cost of the item, its residual value at the end of the term and the time value or profit margin for the money being invested in purchasing the product to be leased for the intended term. This type of transaction is similar to the contractum trinius, a legal maneuver used by European bankers and merchants during the middle ages to sidestep the Church's prohibition on interest bearing loans. In a contractum, two parties would enter into three concurrent and interrelated legal contracts, the net effect being the paying of a fee for the use of money for the term of the loan(6).

4. Good credit scorewiil help to extended loan on a goodwill basis, and the debtor is only required to repay the amount borrowed. However, the debtor may, at his or her discretion, pay an extra amount beyond the principal amount of the loan (without promising it) as a token of appreciation to the creditor(7). In the case that the debtor does not pay an extra amount to the creditor, this transaction is a true interest-free loan.

\section{RESEARCH BACKGROUND}

Mandansky (1960) gave conditions for the equality of the expected value of the objective function for the optimal solution and the value of the objective function for the approximate solution; bounds on these values were also given. In addition, the relation between this problem and a related problem, where one makes an observation on the "right- hand side" and solves the (non-stochastic) linear programming problem based on this observation(2).

Fourer et al., (1995) described extensions to an algebraic modeling language that encompass piecewise-linear, network and related structures. Their emphasis is on the modeling considerations that motivate these extensions, and on the design issues that arise in integrating these extensions with the general-purpose features of the language. They observe that extensions sometimes make models faster to translate as well as to solve, and that they permit a "column-wise" formulation of the constraints as an alternative to the "row-wise" formulation most often associated with algebraic languages(3).

Greenberg et al., (1986) developed a framework for model formulation and analysis to support operations and management of large-scale linear programs from the combined capabilities of camps and analyze. Both the systems were reviewed briefly and the interface which integrates the two systems was then described. The model formulation, matrix generation, and model management capability of camps and the complementary model and solution analysis capability of analyze were presented within a unified framework. Relevant generic functions were highlighted, and an example was presented in detail to illustrate the level of integration achieved in the current prototype system(4).

Sinha et al., (2003) proposed a modified fuzzy programming method to handle higher level multilevel decentralized programming problems (ML (D) PPs). They presented a simple and practical method to solve the same. This method overcomes the subjectivity inherent in choosing the tolerance values and the membership functions(5). 
Wu et al., (2000) proposed a neural network model for linear programming that is designed to optimize radiotherapy treatment planning (RTP). This kind of neural network can be easily implemented by using a kind of 'neural' electronic system in order to obtain an optimization solution in real time.

Konickova (2006) said a linear programming problem whose coefficients are prescribed by intervals is called strongly unbounded if each linear programming problem obtained by fixing coefficients in these intervals is unbounded(6). In the main result of the paper a necessary and sufficient condition for strong unboundedness of an interval linear programming problem was described.

Biswal et al., (1998) developed an approach to solve probabilistic linear programming problems with exponential random variables. The first step involves obtaining the probability density function (p.d.f.) of the linear combination of $\mathrm{n}$ independent exponential random variables. Probabilistic constraints are then transformed to the deterministic constraints using the p.d.f. The resulting non-linear deterministic model is then solved using a non-linear programming solution $\operatorname{method}(7)$.

\section{A. Linear Programming for Bank Portfolio Management}

Various portfolio theories have been propounded for the management of bank funds. Ronald Robinson (1961) proposed four priorities of the use of banks funds. These include primary reserves, (or protective investment), loans and advances (customer credit demand) and investment account (open market investment for income) in descending order of priority. His assessment has been fully supported in other works by Sheng-Yi and Yong (1988)(9). A bank has to place primary reserves at the top of the priority in order to comply with the minimum legal requirement, to meet any immediate withdrawal demand by depositors and to provide a means of clearing cheques and credit obligations among banks. Secondary reserves include cash items from banks, treasury bills and other short-term securities. Bank should have to satisfy customers' loan demand before allocating the balance of the funds in the investment market.

Loans and investment are in fact complementary. According to Robinson, (1961) investment should be tailored to the strength, seasonality and character of loan demand. He reiterated that banks that experience sharp seasonal fluctuations in loan demand need to maintain more liquidity in their investment program(10). Moreover, during a boom when loan demand is high and credit-worthy customers are available, banks should allocate more funds to loans and fewer funds to investment, and vice versa during recession when loan demand is low.

According to Robinson, the crucial banking problem is to resolve the conflict between safety and profitability in the employment of bank funds. The conflict is essentially the problem between liquidity and the size of the earning assets. Robinson suggested that where there is a conflict between safety and profitability, it is better to err on the side of safety.

The best practice is identifying procedures that can bring out the optimal mixture of management of banks funds. According to Tobin (1965) portfolio theory can be applied to bank portfolio management in that a bank would maximize the rates of return of its portfolio of assets, subject to the expected degree of risk and liquidity. Chambers and Charnes (1961) applied linear programming analysis on the consolidated balance sheets of commercial banks in Singapore for the period 1978-1983. The results show that by large banks do not try to maximize the returns of their portfolios, subject to legal, policy, bounding and total assets constraints, which denote riskiness and liquidity of the portfolio of assets. In a direct way, banks conform to the portfolio choice theory; they have to balance yield and liquidity against security. The pointed out that although the computer cannot replace a manager, linear programming can serve as a useful guide.

\section{4, 1 Probability of Loss on Loan Portfolio}

According to Klaus Rheinberger and Martin Summer(2011) in their credit risk portfolio models, three parameters drives loan losses: The probability of default by individual obligors (PD), the loss given default (LGD) and the exposure at default (EAD). While the standard credit risk models focus on modeling the PD for a given LGD, a growing recent literature has looked closer into the issue of explaining LGD and of exploring the consequences of dependencies between PD and LGD. This literature is surveyed in Altman et al; (2005). Most of the papers on the issue of dependency between PD and LGD have been written for US data and usually find strong correlations between these two variables. The first papers investigating the consequences of these dependencies for credit portfolio risk analysis were Frye (2000a) and Frye (2000b) using a credit risk 
model suggested by Finger (1999) and Gordy (2000). The authors used a different credit risk model in the tradition of actuarial portfolio loss models and focus directly on two risk factors: an aggregate PD and an aggregate API as well as their dependence. The authors used this approach because their interest was to investigate the implications of some stylized facts on asset prices and credit risk that have frequently been found in the macroeconomic literature for the risk of collateralized loan portfolios(7). The authors also believe that the credit risk model we use gives us maximal flexibility with assumptions about the distribution of systematic risk factors.

\section{METHODOLOGY}

The classical approach to portfolio optimization is based on these two conflicting optimization criteria: minimizing the risk of a portfolio and maximizing expected return of the portfolio. Return and risk are these items are in conflict of each other and finding a best portfolio structure that give the highest return and lowest risk is not impossible. One might find other efficient portfolio that yields higher return for the same risk, or lower risk for the same return.

Generally, two objectives, expected return and variance of the portfolio, are in conflict and cannot be at their optimal levels simultaneously. So Markowitz (1994) described a new method which avoids actual computation of the covariance matrix and Konno
(1990) solved the risk quadratic function by reducing it to a linear programming and proposed a piecewise approach(10).

A linear programming model helps the business community to maximize the profit by using the available resources or to minimize the cost of expenses. Linear programming is a mathematical technique that deals with the optimization (maximizing or minimizing) of a linear function known as objective function subject to a set of linear equations or inequalities known as constraints. It is a mathematical technique which involves the allocation of scarce resources in an optimum manner, on the basis of a given criterion of optimality. The technique used here is linear programming because the decision variables in any given situation generate straight line when graphed. It is also programming because it involves the movement from one feasible solution to another until the best possible solution is attained. decision variables usually represent things that can be adjusted or controlled. An objective function can be defined as a mathematical expression that combines the variables to express goal and the constraints are expressions that combine variables to express limits on the possible solutions. In general the linear programming model can be formulated as follows (11):

Objective function of linear function which is maximize or minimized:

$$
Z \square \square C_{j} Z_{j} \square \square 1
$$

1. The constraints equations will be represented in " $\leq$ "for maximization model and for the minimization model it will have." $\geq " m$

2. The Non negativity constraints:

$$
\begin{aligned}
& X_{j} \square 0 \\
& \mathrm{i}=1,2,3, \ldots, \mathrm{m} \text { and } \mathrm{j}=1,2,3, \ldots, \mathrm{n}
\end{aligned}
$$

3. STEP 6 :Go to step 3.

\section{PROPOSED MODEL}

Operating research model can be defined as follow: 
$\mathrm{i}=$ Type of economics sector like Agriculture, Mining and Industry and so on. $\mathrm{k}=$ Type of loan, like Future buying, Paternership

$1=$ Loan maturity

$\mathrm{m}=$ Type of economics sector (Private or Governmental)

\section{A. The objective of the bank:}

The object is to maximize its return and minimize risk that we consider (a) as interest rate and (c) as bad debt rate so define objective function as follow(12):

$\begin{array}{llll}n & j & p & q\end{array}$

$\operatorname{MaxZ} \square \square \square \square \square\left[a X_{i k l m} \square b X_{i k l m}\right]$

$i \square 1 k \square 1 l \square 1 m \square 1$

\section{B. Budget constraints:}

The most important source in banks is capital so the maximum amount that intended to facilitate is (w) Rials.

$0.075 X_{1} \square 0.103 X_{2} \square 0.103 X_{3} \square 0.075 X_{4} \square 0.075 X_{5} \square 0.075 X_{6} \square 0.075 X_{7} \square 0.095 X_{8} \square 0.09$

$X_{1} \square X_{2} \square X_{3} \square X_{4} \square X_{5} \square X_{6} \square X_{7} \square X_{8}$

$\mathrm{i}, 1$ and $\mathrm{m}$ not available in other bank and are secret information so we assume They are fixed, so decision variables define as follow:

$\mathrm{X}_{1}=$ Future buying

$\mathrm{X}_{2}=$ Change of ownership less than 2 years

$\mathrm{X}_{3}=$ Future buying more than 2 years

$\mathrm{X}_{4}=$ Partnership $18 \%$

$\mathrm{X}_{5}=$ Partnership $19 \%$

$\mathrm{X}_{6}=$ Partnership 20\%

$\mathrm{X}_{7}=$ Partnership $21 \%$

$\mathrm{X}_{8}=$ Good credit score

\section{Board of directors' constraint:}

The main task of the board of directors is determining the strategy and policies; one of these strategies is to determine the volume of loans. For example competition with other banking institutions in the area requires that:

1. $75 \%-85 \%$ of the bank's resources can be used for bank loans.

2. Allocate at least $50 \%$ of the total funds to Future buting loan and Partnership loan

3. To optimize profit Future buying loan must be at least greater than $50 \%$ of other loans

4. The sum of Future buying loan and Good credit score loan must be at least greater than 50\% of Partnership

5. The sum of Future buying loan and Good credit score loan must be at least $25 \%$ of the total funds.

6. The bank also stated that the total ratio for the bad debt on all loans may not exceed 0.09 .

We analyze the data taken from other bank financial statement. 85\% of consumable sources are 530410 Billion rupees and bank is obligated to grant loans to different clientele. The interest rate charged by the central bank, 
and the probability of bad debt estimated from past years financial statement. Bad debts are unrecoverable and hence produce no interest revenue (13).

The objective of the other Bank can be defined as follows:

Max $Z=\% 24 X_{1}+\% 14 X_{2}+\% 15 X_{3}+\% 18 X_{4}+\% 19 X_{5}+\% 20 X_{6}+\% 21 X_{7}+\% 4 X_{8}-0.075 X_{1}-0.103 X_{2}-$ $0.103 \mathrm{X}_{3}-0.075 \mathrm{X}_{4}-0.075 \mathrm{X}_{5}-0.075 \mathrm{X}_{6}-0.075 \mathrm{X}_{7}-0.095 \mathrm{X}_{8}$

The problem has seven constrains:

1. Limit on total funds available $X_{1}+X_{2}+X_{3}+X_{4}+X_{5}+X_{6}+X_{7}+X_{8} \square 530410$

2. Limit on loan and Partnership loan

$$
\begin{aligned}
& X_{1}+X_{4}+X_{5}+X_{6}+X_{7} \square 0.5 \square 530410 \\
& X_{1}+X_{4}+X_{5}+X_{6}+X_{7} \square 265205
\end{aligned}
$$

3. Limit on Future buying

$$
\begin{aligned}
& \mathrm{X} 1 \square 0.5\left(\mathrm{X}_{2}+\mathrm{X}_{3}+\mathrm{X}_{4}+\mathrm{X}_{5}+\mathrm{X}_{6}+\mathrm{X}_{7}+\mathrm{X}_{8}\right) \\
& \mathrm{X} 1-0.5 \mathrm{X}_{2}-0.5 \mathrm{X}_{3}-0.5 \mathrm{X}_{4}-0.5 \mathrm{X}_{5}-0.5 \mathrm{X}_{6}-0.5 \mathrm{X}_{7}-0.5 \mathrm{X}_{8} \square 0
\end{aligned}
$$

4. Limit on Partnership and Future buying loans

$$
\begin{aligned}
& \mathrm{X} 1+\mathrm{X} 8 \square 0.5\left(\mathrm{X}_{4}+\mathrm{X}_{5}+\mathrm{X}_{6}+\mathrm{X}_{7}\right) \\
& \mathrm{X} 1+\mathrm{X} 8-0.5 \mathrm{X}_{4}-0.5 \mathrm{X}_{5}-0.5 \mathrm{X}_{6}-0.5 \mathrm{X}_{7} \square 0
\end{aligned}
$$

5. Limit on Future buying loan and Good credit score loan $\mathrm{X}_{1}+\mathrm{X}_{8} \square 0.25 \square 530410$

$$
\mathrm{X}_{1}+\mathrm{X}_{8} \square 132602
$$

6. Limit on bad debts

$$
0.075 X_{1} \square 0.103 X_{2} \square 0.103 X_{3} \square 0.075 X_{4} \square 0.075 X_{5} \square 0.075 X_{6} \square 0.075 X_{7} \square 0.095 X_{8}
$$

$X_{1} \square X_{2} \square X_{3} \square X_{4} \square X_{5} \square X_{6} \square X_{7} \square X_{8}$

$$
-0.015 \mathrm{X}_{1}+0.053 \mathrm{X}_{2}+0.053 \mathrm{X}_{3}-0.015 \mathrm{X}_{4}-0.015 \mathrm{X}_{5}--0.015 \mathrm{X}_{6}--0.015 \mathrm{X}_{7}+0.005 \mathrm{X}_{8} \leq 0
$$

7. Non-negativity

$\mathrm{X}_{1} \square 0, \mathrm{X}_{2} \square 0, \mathrm{X}_{3} \square 0, \mathrm{X}_{4} \square 0, \mathrm{X}_{5} \square 0, \mathrm{X}_{6} \square 0, \mathrm{X}_{7} \square 0, \mathrm{X}_{8} \square 0$

$\operatorname{Max} Z=0.165 \mathrm{X}_{1}+0.037 \mathrm{X}_{2}+0.047 \mathrm{X}_{3}+0.105 \mathrm{X}_{4}+0.115 \mathrm{X}_{5}+0.125 \mathrm{X}_{6}+0.135 \mathrm{X}_{7}-0.055 \mathrm{X}_{8}$

St:

$$
\begin{aligned}
& X_{1}+X_{2}+X_{3}+X_{4}+X_{5}+X_{6}+X_{7}+X_{8} \square 530410 X_{1}+X_{4}+X_{5}+X_{6}+X_{7} \square 265205 \\
& X_{1}-0.5 X_{2}-0.5 X_{3}-0.5 X_{4}-0.5 X_{5}-0.5 X_{6}-0.5 X_{7}-0.5 X_{8} \square 0 \\
& X_{1}+X_{8}-0.5 X_{4}-0.5 X_{5}-0.5 X_{6}-0.5 X_{7} \square 0 X_{1}+X_{8} \square 132602 \\
& 0.025 X_{1}+0.053 X_{2}+0.023 X_{3}+0.025 X_{4}+0.025 X_{5}+0.025 X_{6}+0.025 X_{7}+0.045 X_{8} \leq 0
\end{aligned}
$$

\section{CONCLUSION}

There are several things to observe about this output data, for maximizing profit and minimizing risk, with assumed circumstances, amount should be 265205 billion rupees and we should not use other loans. The reduced costs for X1(SPartnership) and X3(Change of owner ship more than 2 years) are zero. This is 
because the reduced costs are the objective function coefficients of the original variables, and since are basic at the optimum, their objective function coefficients must be zero when the tableau is put into proper form. This is always true.

It is recommended that Bank of Baroda should be educated to employ mathematicians to use scientific methods to find an appropriate mathematical model to help them disburse funds of the banks more efficiently.

\section{References}

1) Greenberg, H.J., Lucaus, C. \& Mitra, G. (1986), "Computer - assisted Modeling and Analysis of Linear Programming Problems: Towards a unified framework", IMA Journal of Management Mathematics 1, 251-265.

2) Kantorovich, L.V.(1940), "A new method of solving some classes of external problems", Doklady Akad Sci USSR 28, 211-214.

3) Klaassen, P. (1998), "Financial asset-pricing theory and stochastic programming models for asset-liability management: A synthesis", Management Science 44, 31-48.

4) Konickova, J. (2006), "Strong Unboundedness of interval Linear Programming Problems", 12th GAMM - IMACS International Symposium, ISBN:0-7695-2821-X, doi:10.1109/SCAN.2006.42.

5) Konno, H. (1990), "Piecewise linear risk function and portfolio optimization", Journal of the Operational Research Society of Japan 33 (2), $139-156$.
6) Mandansky, A. (1960), "Inequalities for stochastic Linear Programming Problems", Management Science 6, $197-204$.

7) Markowitz, H., Todd, P., Xu, G \& Yamane, Y. (1994), "Fast computation of mean-variance efficient sets using historical covariance", Journal of Financial Engineering 1 (2), 117-132.

8) Rheinberger, Klaus \& Summer, Martin, (2012), "Credit Risk in General Equilibrium", ECB Working Paper No. 1445, Available: http://ssrn.com/abstract=2081663.

9) Robinson, R.I. (1961), “The Management of Bank funds",New York, McGraw-Hill, Available: http://www.econis.eu/PPNSET?PPN=020308213

10) Sinha, S.B \& Sinha, S. (2003), “A linear Programming approach for Linear multi - level Programming Problems" , The Journal of the Operational Research Society 55( 3), 312-316.

11) Tobin, J.(1965)," The Theory of portfolio Selection", RT Journal Article, Macmillan Press. Optimal Bank Loan Portfolio In Iranian's Banks (Based Linear Programming Modelling) Mohammad Javad Mohagheghnial Mohammad Shirgholami2*

12) Yong,W.Y \& Sheng-Yi, L. (1988), "Linear programming for bank portfolio management in Singapore", Asia Pacific Journal of Management $5(2), 110-114$.

13) $\mathrm{Wu}, X .$, Zhu, Y \& Luo, L. (2000), "Linear Programming base on neural networks for radiotherapy treatment planning" , Physics in Medicine and Biology 45(3), 719-728, doi:10.1088/0031-9155/45/3/310 